\title{
Comparison of Predicted and Measured Attenuation of Turbine Noise from a Static Engine Test
}

\author{
Eugene W. Chien, Marta Ruiz and Jia Yu \\ Goodrich Aerostructures Group, Chula Vista, CA. 91910 \\ Bruce L. Morin, Dennis Cicon and Paul S. Schweiger \\ Pratt \& Whitney, East Hartford, CT. 06108 \\ Douglas M. Nark \\ NASA Langley Research Center, Hampton, VA. 23681
}

\section{Introduction}

Aircraft noise has become an increasing concern for commercial airlines. Worldwide demand for quieter aircraft is increasing, making the prediction of engine noise suppression one of the most important fields of research.

The Low-Pressure Turbine (LPT) can be an important noise source during the approach condition for commercial aircraft. The National Aeronautics and Space Administration (NASA), Pratt \& Whitney (P\&W), and Goodrich Aerostructures (Goodrich) conducted a joint program to validate a method for predicting turbine noise attenuation. The method includes noise-source estimation, acoustic treatment impedance prediction, and in-duct noise propagation analysis.

Two noise propagation prediction codes, Eversman Finite Element Method (FEM) code [1] and the CDUCT-LaRC [2] code, were used in this study to compare the predicted and the measured turbine noise attenuation from a static engine test.

In this paper, the test setup, test configurations and test results are detailed in Section II. A description of the input parameters, including estimated noise modal content (in terms of acoustic potential), and acoustic treatment impedance values are provided in Section III. The prediction-to-test correlation study results are illustrated and discussed in Section IV and V for the FEM and the CDUCT-LaRC codes, respectively, and a summary of the results is presented in Section VI.

\section{Test Description}

\section{Description of Test Configurations and Results}

Engine noise testing was conducted at Pratt \& Whitney's C-11 test stand in West Palm Beach, Florida. Figure 1 shows the far-field microphone array, which consisted of 32 microphones at a 150 - $\mathrm{ft}$ radius around the engine. The microphones were spaced in 5degree increments over a range of angles between 5 and 160 degrees from the inlet axis of the engine. The engine was a PW4000-94, which has a four-stage low-pressure turbine with blade counts of 128, 130, 126 and 128 (front-to-back). The PW4000-94 family of engines has been in production since 1987. 


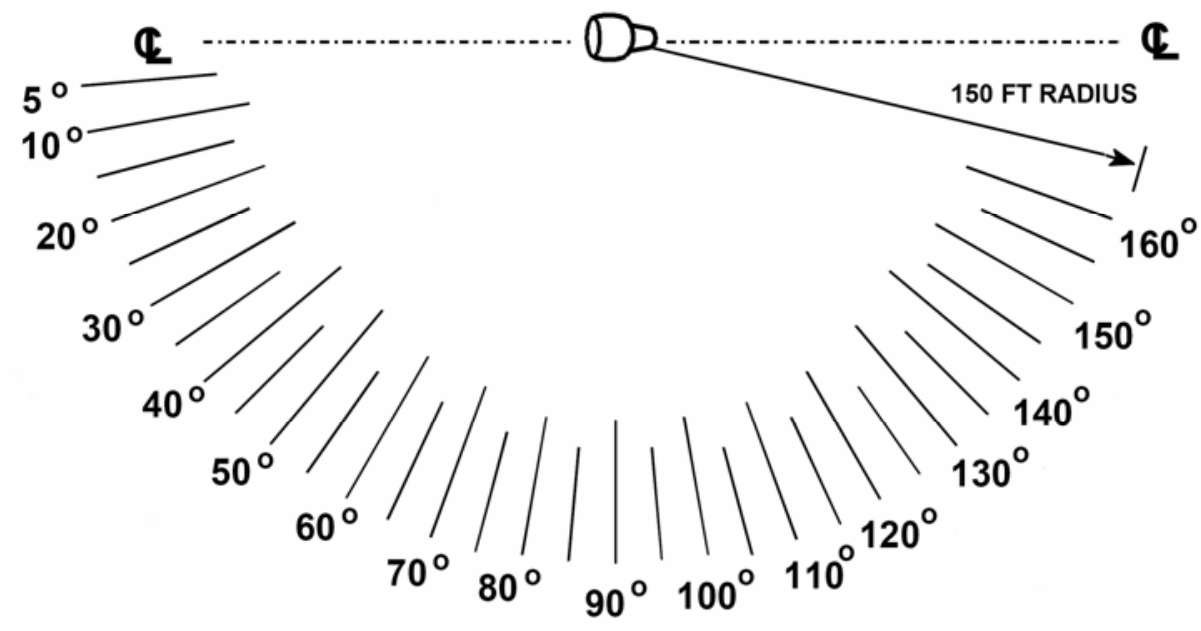

Figure 1: Far field microphone array at P\&W C-11 Test Stand.

Figure 2 shows a cross section of the turbine exhaust duct, which includes acoustic liners on the nozzle and plug.

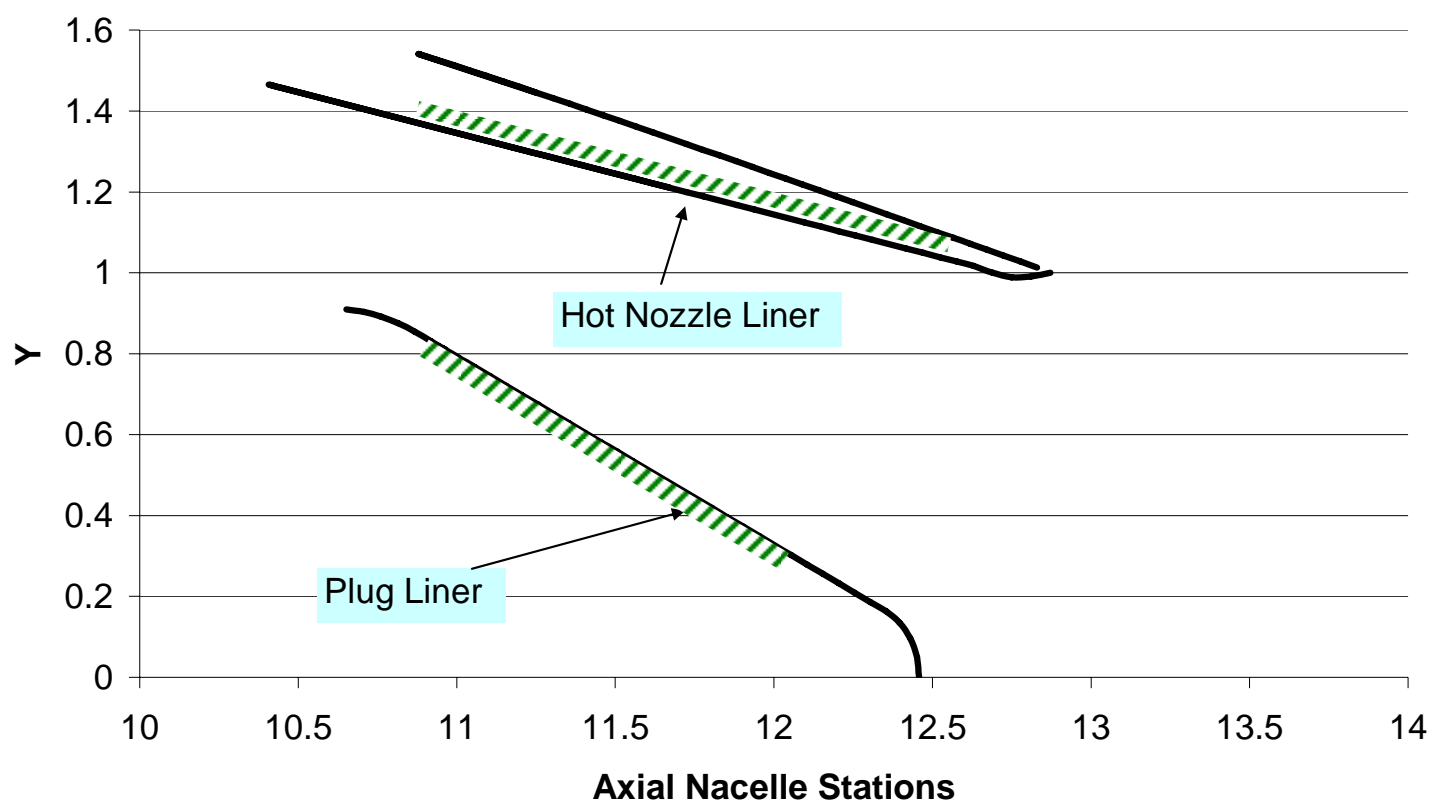

Figure 2: Turbine exhaust duct geometry and liner locations. Dimensions are normalized by the exit diameter of the duct.

To determine the effect of the acoustic liners on turbine noise suppression, the following four configurations were tested:

Configuration 1: hardwall nozzle and hardwall plug

Configuration 2: treated nozzle and hardwall plug

Configuration 3: hardwall nozzle and treated plug

Configuration 4: treated nozzle and treated plug. 


\section{Hardwall Spectra}

Figure 3 shows the sound pressure spectra (SPL) measured for Configuration 1 (hardwall nozzle, hardwall plug) at angles of 100, 115 and 130 degrees from the inlet axis, with the turbine operating at $62 \%$ of its design speed. Corrections were applied to the spectra to remove the effect of atmospheric attenuation [4, 5]. The spectra are presented versus engine order, which is defined as,

$$
\begin{gathered}
\text { EO }=\frac{f}{\Omega} \\
\text { where } \\
f=\text { frequency }(\mathrm{Hz}) \\
\Omega=\text { rotational speed }(\mathrm{rev} / \mathrm{sec})
\end{gathered}
$$

To focus attention on turbine noise, the abscissa has been limited to engine orders between 100 and 156. The solid black lines represent the measured engine spectra, and the dashed blue lines represent the estimated turbine spectra. The estimated turbine spectra are based on Pratt \& Whitney's empirical method for separating turbine noise from measured engine noise.

The sound pressure spectra are characterized by a broad haystack and tones at engine orders of 126, 128 and 130. The tones are most apparent at the 100-degree angle. However, the tones are barely visible at the 115-degree angle, and are not observed at the 130-degree angle. The tones correspond to the blade-passage frequencies of the lowpressure turbine. The haystack is due to frequency scattering that occurs when the turbine tones pass through the primary and secondary shear layers [6]. The spectral characteristics shown in Figure 3 are qualitatively similar for all configurations and speeds presented in this paper.
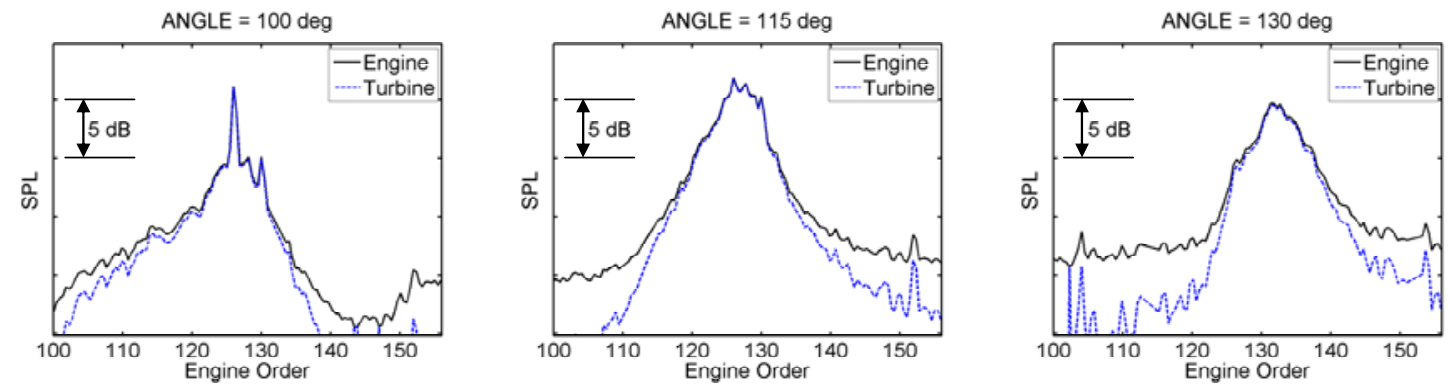

Figure 3: Sound-pressure spectra, Configuration 1, 62\% design speed.

\section{Liner Effect}

For each configuration, turbine sound-power spectra (PWL) were determined by integrating the turbine sound-pressure spectra (SPL) over the polar array of microphones. The integration was limited to angles between 85 and 145 degrees from the inlet axis. The turbine overall sound-power level (OAPWL) was determined by integrating the turbine sound-power spectra over the range of engine orders shown in Figure 3. Consequently, the overall sound-power level represents the power associated with the 
blade-passage frequencies and haystack produced by all stages of the LPT. Liner insertion loss was determined by subtracting the treated overall sound-power level (i.e. Configurations 2 through 4) from that of the fully hardwall configuration (i.e. Configuration 1).

Figure 4 shows the turbine sound-power spectra for each configuration with the turbine operating at $62 \%$ of its design speed. Figure 5 shows the turbine overall sound-power level versus percent design speed. In Figure 5, the symbols represent data points, and the solid lines represent $3^{\text {rd }}$-order polynomial curve fits of the data. As expected, Configuration 4 (treated nozzle, treated plug) has the largest insertion loss, which is between 6 and $7 \mathrm{~dB}$ over the range of speeds shown. The insertion loss of Configuration 2 (treated nozzle, hardwall plug) is between 4 and $5 \mathrm{~dB}$, and the insertion loss of Configuration 3 (hardwall nozzle, treated plug) is approximately $1 \mathrm{~dB}$. These results are consistent with the expectation that the insertion loss should be proportional to the amount of treated area in the turbine exhaust duct.

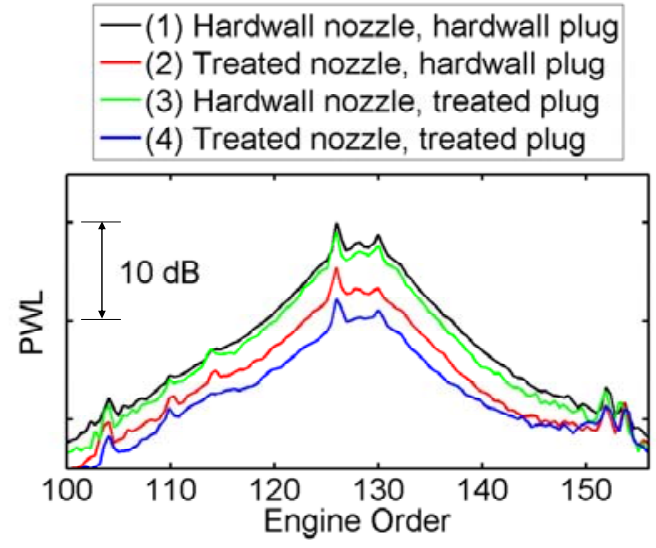

Figure 4: Turbine sound power spectra at $62 \%$ design speed.
- (1) Hardwall nozzle, hardwall plug

$\nabla$ (2) Treated nozzle, hardwall plug

$\Delta$ (3) Hardwall nozzle, treated plug

- (4) Treated nozzle, treated plug

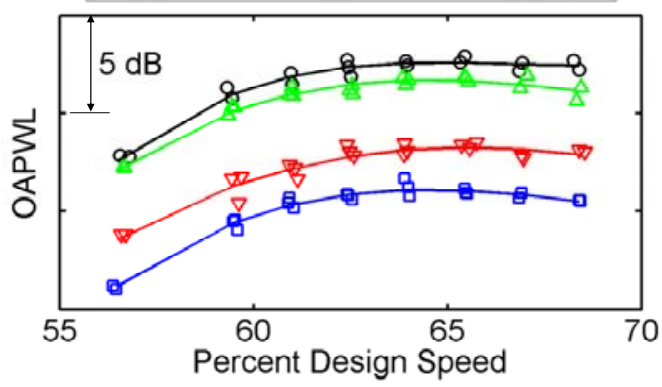

Figure 5: Turbine overall sound power level.

Table 1 shows the insertion loss at the engine speeds used for the FEM and CDUCT analyses. The tabulated insertion loss values are based on the curve fits shown in Figure 5.

\begin{tabular}{|c|c|c|c|}
\hline \multirow{2}{*}{$\begin{array}{c}\text { Turbine Speed } \\
\text { re. Design Pt }\end{array}$} & \multicolumn{3}{|c|}{ Measured Insertion Loss (dB) } \\
\cline { 2 - 4 } & $\begin{array}{c}\text { Config. 2, } \\
\text { treated nozzle, } \\
\text { hardwall plug }\end{array}$ & $\begin{array}{c}\text { Config. 3, } \\
\text { hardwall nozzle, } \\
\text { treated plug }\end{array}$ & $\begin{array}{c}\text { Config. 4, } \\
\text { treated nozzle, } \\
\text { treated plug }\end{array}$ \\
\hline $56 \%$ & 4.0 & 0.5 & 6.4 \\
\hline $62 \%$ & 4.6 & 0.9 & 6.5 \\
\hline $68 \%$ & 4.5 & 1.3 & 6.9 \\
\hline
\end{tabular}

Table 1: Measured insertion loss 


\section{Description of Input Parameters for FEM and CDUCT Codes}

\section{Estimated Mode Content}

Reference [7] describes an inverse method for identifying the acoustic modal structure in a turbofan inlet using far-field noise measurements and high-fidelity, aeroacoustic radiation simulations. For the present study, that method was adapted for turbine exhaust noise, and used to estimate the mode content for Configuration 1 (hardwall nozzle, hardwall plug) at the $62 \%$ speed condition. The aeroacoustic radiation simulations were done using the Eversman aft radiation code. The assumed mode set included all rotorstator interaction modes that could contribute to the tone at $\mathrm{EO}=128$. The mode amplitudes were determined by "best-fitting" the radiation calculations to the measured turbine-noise SPL directivity shown in Figure 6. The resultant velocity potential amplitudes are shown in Table 2 for the 15 largest contributing modes. This estimated mode content was used in the subsequent FEM and CDUCT analyses.

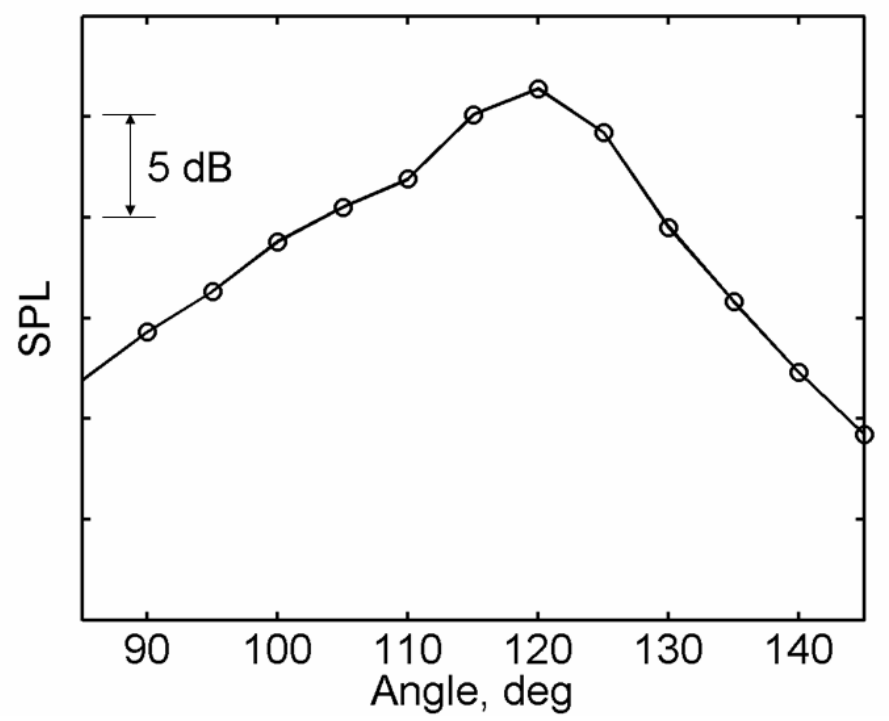

Figure 6: SPL directivity pattern used to estimate mode content for Configuration 1 at $62 \%$ design speed.

\begin{tabular}{|c|c|c|c|c|c|}
\hline \multirow{2}{*}{$\begin{array}{c}\text { Circumferential } \\
\text { Mode Order }\end{array}$} & $\mathrm{n}=0$ & $\mathrm{n}=1$ & $\mathrm{n}=2$ & $\mathrm{n}=3$ & $\mathrm{n}=4$ \\
\hline $\mathrm{m}=8$ & $8.82 \mathrm{E}-05$ & $2.39 \mathrm{E}-06$ & $7.50 \mathrm{E}-05$ & $8.57 \mathrm{E}-05$ & $6.40 \mathrm{E}-04$ \\
\hline $\mathrm{m}=-4$ & $7.95 \mathrm{E}-06$ & $2.41 \mathrm{E}-04$ & $3.75 \mathrm{E}-04$ & $9.66 \mathrm{E}-05$ & $1.92 \mathrm{E}-05$ \\
\hline $\mathrm{m}=11$ & $2.99 \mathrm{E}-04$ & $2.71 \mathrm{E}-04$ & $6.76 \mathrm{E}-04$ & $6.40 \mathrm{E}-04$ & $1.88 \mathrm{E}-04$ \\
\hline
\end{tabular}

Table 2: Estimated velocity potential amplitudes for Configuration 1 at $62 \%$ design speed, $\mathrm{EO}=128$.

\section{Estimated Liner Impedance}

The impedance values of the hot nozzle and plug liners, Figure 2, were predicted using the Goodrich perforate liner impedance model [8]. The liner impedance is defined as the 
ratio of the local acoustic pressure "P" acting on the surface of the liner to the associated particle velocity "V" of the fluid normal to the surface (Pn \& Vn):

$$
\mathrm{Zn}(\text { Normal Impedance })=\mathrm{Pn} / \mathrm{Vn}=(\mathrm{Pi}+\mathrm{Pr}) /(\mathrm{Vi}+\mathrm{Vr})
$$

where Pi \& Vi are incoming wave and Pr \& Vr are reflecting wave acoustic pressure and particle velocity normal to the surface. Liner impedance is a function of sound pressure, liner geometrical dimensions, grazing flow Mach number, and boundary layer thickness. It is not dependent on the grazing flow direction. The general equation can be expressed as follows:

$$
\mathrm{Z} / \rho c=\mathrm{R}+\mathrm{jX}=\mathrm{R}_{\mathrm{O}}+\mathrm{R}_{\mathrm{Of}}+\mathrm{S}_{\mathrm{r}} \mathrm{V}_{\mathrm{p}}+\mathrm{R}_{\mathrm{cm}}\left(\mathrm{V}_{\mathrm{cm}}\right)+\mathrm{j}\left[\mathrm{X}_{\mathrm{m}}+\mathrm{S}_{\mathrm{m}} \mathrm{V}_{\mathrm{p}}+\mathrm{X}_{\mathrm{em}}\left(\mathrm{V}_{\mathrm{cm}}\right)-\cot (\mathrm{kh})\right]
$$

Where,

$\mathbf{Z} / \rho \boldsymbol{c}$ is a complex number representing normalized Impedance

$\mathbf{R}$ is normalized acoustic resistance; $\mathbf{X}$ is normalized acoustic reactance

$\mathbf{j}$ is $\sqrt{ }-\mathbf{1}$ the unit imaginary number; $\boldsymbol{\rho}$ is air density and $\boldsymbol{c}$ is the speed of sound

$\rho c$ is defined as a characteristic impedance (unit: cgs- Rayl)

$\mathbf{R}_{\mathbf{0}}$ is non-frequency dependent linear acoustic resistance

$\mathbf{R}_{\mathbf{o f}}$ is frequency dependent linear acoustic resistance

$\mathbf{S}_{\mathbf{r}}$ is the non-linear resistance slope

$\mathbf{V}_{\mathbf{p}}$ is the root-mean-square particle velocity over the entire frequency range in $\mathrm{cm} / \mathrm{sec}$

$\mathbf{V}_{\mathbf{~} \mathbf{m}}$ is Mach Number

$\mathbf{R}_{\mathbf{c m}}\left(\mathbf{V}_{\mathbf{c m}}\right)$ is the grazing flow induced acoustic resistance

$\mathbf{X}_{\mathbf{m}}$ is mass reactance (including ending correction)

$\mathbf{S}_{\mathbf{m}}$ is the non-linear mass reactance slope

$\mathbf{X}_{\mathbf{e m}}\left(\mathbf{V}_{\mathbf{c m}}\right)$ is non-linear mass reactance

$\mathbf{k}$ is the wave number per $\mathbf{c m}$;

$\mathbf{c o t}(\mathbf{k h})$ is the backing cavity reactance, $\mathbf{h}$ is cavity depth $(\mathrm{cm})$

Pratt \& Whitney provided the flow-field information (pressure, temperature, Mach number and displacement thickness) and internal sound-pressure spectra that were used as input to the Goodrich impedance model. The flow-field information was based on a quasi-1D flow calculation that was coupled to a boundary-layer calculation. The internal sound-pressure spectra were based on experimental data acquired in the turbine exhaust duct.

Table 3 presents the computed impedances for the nozzle and the plug liner.

\begin{tabular}{|c|c|c|c|c|c|c|}
\hline \multirow{2}{*}{$\begin{array}{c}\text { Liner } \\
\text { Location }\end{array}$} & \multicolumn{2}{|c|}{$56 \%$ Design Speed } & \multicolumn{2}{c|}{ 62\% Design Speed } & \multicolumn{2}{c|}{ 68\% Design Speed } \\
\cline { 2 - 7 } & $\begin{array}{c}\mathrm{R} \\
\text { (RhoC) }\end{array}$ & $\begin{array}{c}\mathrm{X} \\
\text { (RhoC) }\end{array}$ & $\begin{array}{c}\mathrm{R} \\
\text { (RhoC) }\end{array}$ & $\begin{array}{c}\mathrm{X} \\
\text { (RhoC) }\end{array}$ & $\begin{array}{c}\mathrm{R} \\
\text { (RhoC) }\end{array}$ & $\begin{array}{c}\mathrm{X} \\
\text { (RhoC) }\end{array}$ \\
\hline Nozzle & 0.75 & -0.55 & 0.85 & -0.63 & 0.97 & -0.72 \\
\hline Plug & 0.64 & -0.67 & 0.72 & -0.75 & 0.83 & -0.84 \\
\hline
\end{tabular}

$\underline{\text { Table 3: }}$ Computed liner impedance at EO $=128$. 


\section{Finite Element Method (FEM) Propagation Code Predictions}

NASA and Goodrich along with University Missouri-Rolla structured a program under NASA contract NAS1-00088 to study the deviations of the prediction results using different modal amplitudes and random phase inputs. The study results show that the modal phase inputs would cause significant differences in noise attenuation predictions [3]. G. Zlavog and W. Eversman, also reported the details of the study [1]. In this study, an axi-symmetric geometry model based on the approach described in References [1] and [3] was constructed using the modal contents shown in Table 2 as the noise source. These modal contents in terms of acoustic potential are related to the modal pressure amplitudes by:

$$
p=-\rho_{0}\left[\left(\frac{\partial \phi}{\partial t}\right)+U\left(\frac{\partial \phi}{\partial x}\right)\right]
$$

The finite element model used in the analysis is illustrated in Figure 7. The steady flow velocity was calculated based on the steady flow velocity potential [1] using the mean flow field provided by $\mathrm{P} \& \mathrm{~W}$ at the noise source plane. The calculations were done for a single tone at $\mathrm{EO}=128$. The relative phase of each mode was assigned randomly, and 1000 sets of random phases were used for each configuration.

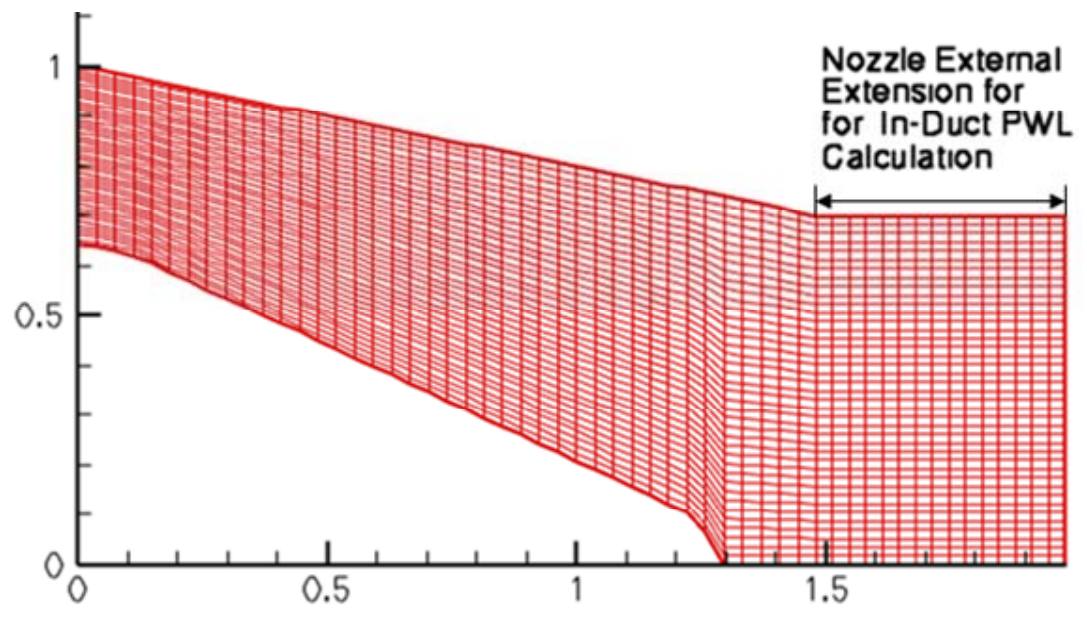

Figure 7: Illustration of Finite Element Model

Figures 8, 9 and 10 show the predicted noise attenuation levels for the treated nozzle and hardwall plug case, the hardwall nozzle and treated plug case, and the treated nozzle and treated plug case. The results are presented as histograms with each bin indicating a range of predicted attenuation levels. The ordinate shows the number of predicted attenuations that occur within each bin. As noted earlier, the total number of occurrences is 1000 for each configuration (i.e. 1000 sets of random-phase assignments).

The histograms clearly show that the phase assumption significantly impacts the predicted attenuation values. For example, the histogram for Configuration 4 (treated nozzle, treated plug) shows that the predicted attenuation ranges from $3.2 \mathrm{~dB}$ to $13.7 \mathrm{~dB}$ depending on the mode assumption. Similar results are observed for the other two 
configurations. Also, the histogram distributions are not Gaussian, and have positive skew for each configuration (i.e. they have an extended tail on the right side of the distribution).

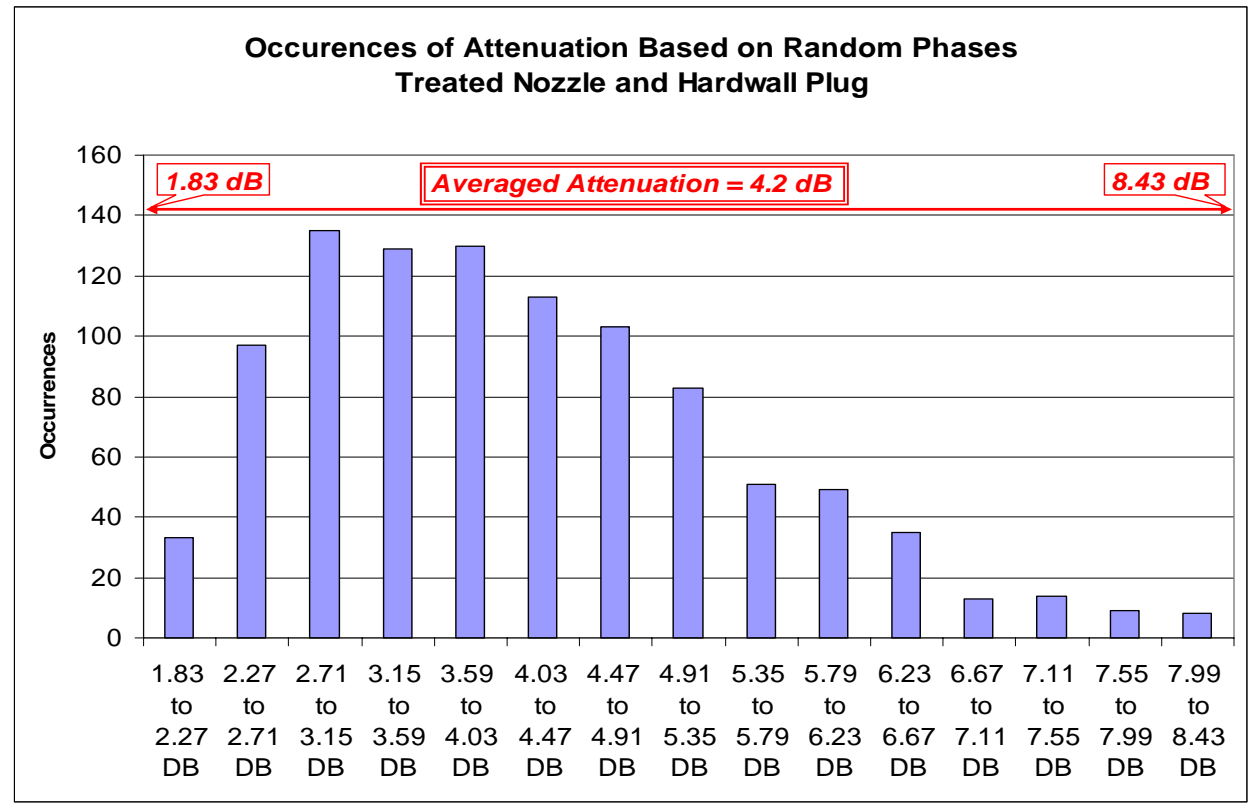

Figure 8: Predicted noise attenuation levels using random phase inputs for the treated nozzle and hardwall plug case, 62\% design speed, EO = 128.

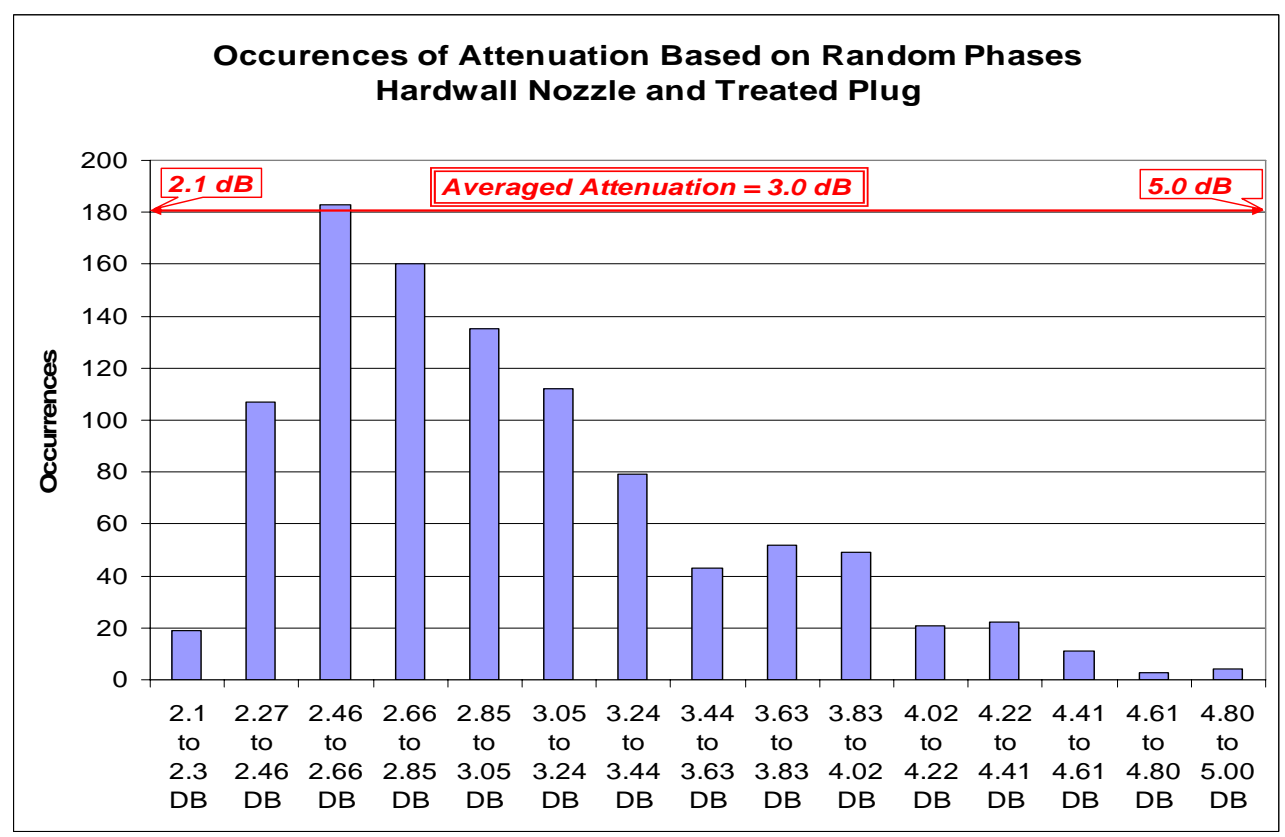

Figure 9: Predicted noise attenuation levels using random phase inputs for the hardwall nozzle and treated plug case, $62 \%$ design speed, EO = 128. 


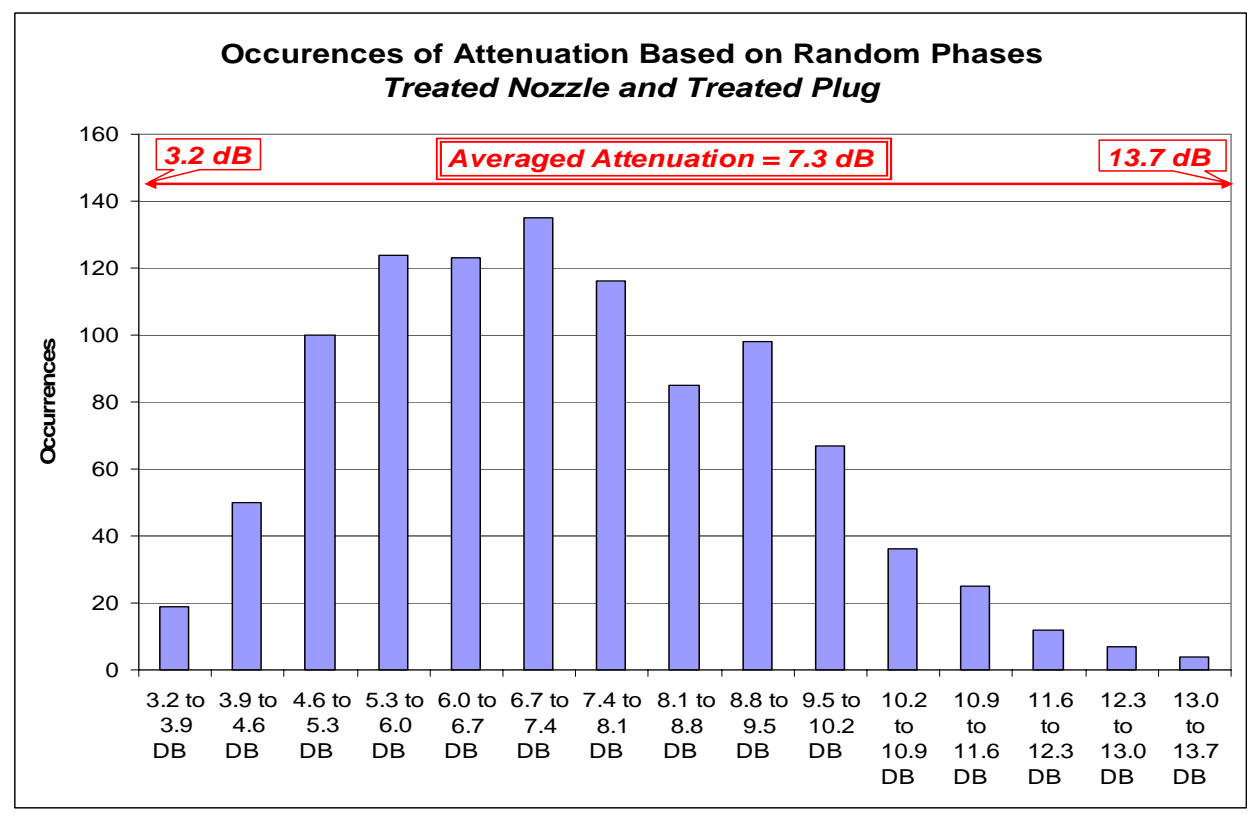

Figure 10: Predicted noise attenuation levels using random phase inputs for the treated nozzle and treated plug case, 62\% design speed, EO = 128.

Table 4 compares the mean predicted attenuation (i.e. the mean of the histograms) to the measured attenuation for each configuration. In comparing predictions to data, it is assumed that the predicted attenuation at $\mathrm{EO}=128$ is representative of the attenuation of the noise produced by all turbine stages combined. This assumption is reasonable because the turbine blade counts are similar for each turbine stage (i.e. between 126 and 130).

\begin{tabular}{|c|c|c|c|c|}
\hline Configuration & Nozzle & Plug & $\begin{array}{c}\text { Mean Predicted } \\
\text { Attenuation } \\
(\mathbf{d B})\end{array}$ & $\begin{array}{c}\text { Measured } \\
\text { Attenuation } \\
(\mathbf{d B})\end{array}$ \\
\hline 2 & Treated & Hardwall & 4.2 & 4.6 \\
\hline 3 & Hardwall & Treated & 3.0 & 0.9 \\
\hline 4 & Treated & Treated & 7.3 & 6.5 \\
\hline
\end{tabular}

Table 4: LPT predicted and measured sound power attenuations at 62\% design speed.

For Configurations 2 and 4, which both have a treated nozzle, the mean predicted attenuations agree well with measured data (within $0.8 \mathrm{~dB}$ ) However, for Configuration 3 , which has a hardwall nozzle and treated plug, the FEM code over predicted the mean attenuation by $2.1 \mathrm{~dB}$ compared to the test data. Moreover, based on the histogram for Configuration 3 (Figure 9), the entire range of predicted attenuations exceeds the measured value. This result indicates that the phase assumption is not the root cause for the discrepancy between the predicted and measured value of attenuation. 
The discrepancy between the predicted and measured attenuation for Configuration 3 may be due to uncertainty in the plug impedance value. As described in Section III, the flow-field information used to compute impedance was based on a quasi-1D flow calculation coupled to a boundary-layer calculation. Subsequent viscous CFD calculations have shown that the boundary-layer displacement thickness on the plug is much larger than that predicted from the boundary-layer calculation. Consequently, the actual plug resistance is probably much less than the value used in the FEM calculation.

\section{CDUCT-LaRC Predictions}

The CDUCT-LaRC [2] duct propagation and acoustic radiation tool was developed to study the internal acoustic propagation within and radiation from complex threedimensional duct geometries. This tool was used to predict the attenuation achieved with the previously described acoustic treatment. The three-dimensional turbine exhaust duct computational grid was created using the CDUCT-LARC meshing capability. Figure 11 shows the mesh between the hot nozzle and the plug.

The mean flow used for the presented predictions was obtained from P\&W viscous flow CFD calculations for the $68 \%$ speed condition. This solution represented a circumferential segment of the tailpipe geometry. The CDUCT-LaRC predictions were performed over the complete 3-D tailpipe geometry. Therefore, the CFD solution was circumferentially averaged and then interpolated onto the CDUCT-LaRC acoustic grid. Both the CFD and acoustic grids incorporated a fictitious plug aft of the tailplug termination to facilitate boundary condition specification. The transition between the tailplug and fictitious plug was smoothed in the CFD grid, whereas a step transition was present in the acoustic grid. While this had minimal effect on the mean flow interpolation, the geometric feature could possibly have some effect on propagation predictions. It should also be pointed out that the CFD solution in this case was the result of viscous calculations. While this is easily incorporated into the CDUCT-LaRC propagation calculations, it does not agree with the inviscid mean flow assumptions of the current CDUCT-LaRC propagation module. In this case however, the mean flow did not include large regions of separated flow and comparison of these predicted attenuations with those incorporating mean flows based on 1-D Mach-area solutions showed minimal changes.

The current propagation module is based on a parabolic approximation to the convected Helmholtz equation, which affords predictions for complex 3-D geometries to be handled with relatively low computational costs. This efficiency comes at the expense of reduced accuracy as modes closer to cut-off are considered and the propagation angle diverges from the preferred angle of the parabolic approximation. Therefore, the capability to utilize a wide angle correction is also included in the module. The use of the wide angle correction can alleviate some of the error due to wide angle propagation, coming at the expense of increased computation time.

Noise propagation of a combination of the first 5 radial modes for $m=8, m=-4$ and $m=11$ (see Table 2) was analyzed using the CDUCT-LaRC prediction tool. In contrast to the FEM predictions discussed in Section IV, where random input phases were used, the relative phase of the various source modes was set to 0.0 and the amplitudes were set to those values provided in Table 2. All calculations were done for a single tone at EO=128. 


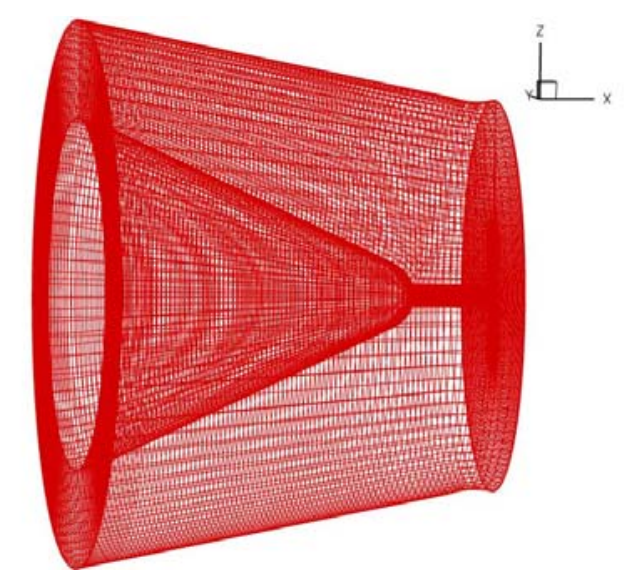

Figure 11: CDUCT turbine exhaust duct mesh.

Figure 12 shows the predicted Sound Pressure Levels for an untreated turbine exhaust duct and for the three treated configurations described in Section II. Table 5 shows the sound power attenuations obtained using CDUCT-LaRC along with the test results. As mentioned in Section IV, when comparing predictions to data, it is assumed that the predicted attenuation at $\mathrm{EO}=128$ is representative of the attenuation of the noise produced by all turbine stages combined.

Even though the CDUCT-LaRC calculations were run with zero-phase between modes, the predicted attenuations agree reasonably well with the data for Configuration 2 and 4 . Furthermore, the CDUCT-LaRC predictions with WAA are within $0.5 \mathrm{~dB}$ of the FEM random-phase predictions. These results are somewhat surprising, and may be fortuitous, given the phase sensitivity that was observed in the FEM calculations. The wide-angle approximation (WAA) increased the predicted attenuation, which improved agreement with test data for Configuration 2, but worsened the agreement for Configurations 3 and 4. Like the FEM code, CDUCT-LaRC over predicts the attenuation for Configuration 3. This discrepancy may be due to uncertainty in the plug impedance (see discussion in Section IV).

A random-phase CDUCT-LaRC study was also conducted similar to the FEM study described in Section IV. The flow field, mode inputs and impedances were the same as previously described, but 1000 cases were run with a random phase assigned to each mode. The wide-angle approximation was not used during the CDUCT-LaRC randomphase study.

Figure 13 shows a histogram of the CDUCT-LaRC attenuation results for Configuration 4 (treated nozzle, treated plug). The predicted mean $(6.1 \mathrm{~dB})$ compares well with the measured attenuation $(6.5 \mathrm{~dB})$, and is close to the zero-phase result $(6.6 \mathrm{~dB})$. The CDUCT-LaRC histogram also agrees well with the FEM code, showing a broad range of attenuation with positive skew. 

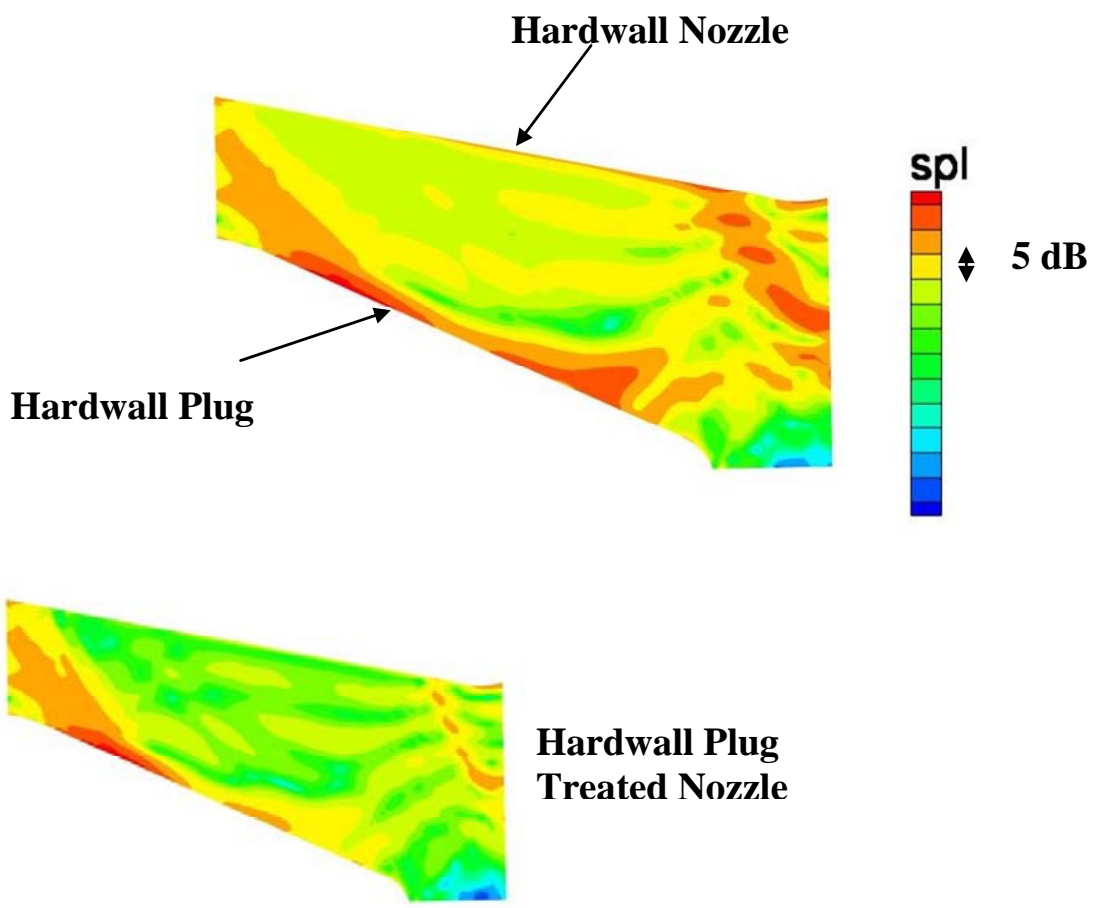

Hardwall Plug

Treated Nozzle

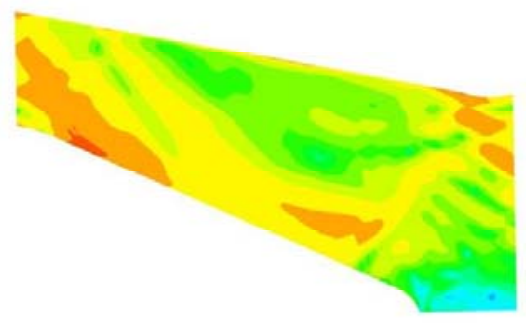

Treated Plug

Hardwall Nozzle

Treated Plug

Treated Nozzle

Figure 12: SPL predictions at EO = 128 for four configurations, 62\% design speed. 


\begin{tabular}{|c|c|c|c|c|c|c|}
\hline Config & Nozzle & Plug & $\begin{array}{c}\text { Percent } \\
\text { Design } \\
\text { Speed }\end{array}$ & $\begin{array}{c}\text { Predicted } \\
\text { Attenuation } \\
\text { (dB) } \\
\text { No WAA }\end{array}$ & $\begin{array}{c}\text { Predicted } \\
\text { Attenuation } \\
\quad(d B) \\
\text { With WAA }\end{array}$ & $\begin{array}{l}\text { Measured } \\
\text { Attenuation } \\
\text { (dB) }\end{array}$ \\
\hline \multirow{3}{*}{2} & \multirow{3}{*}{ Treated } & \multirow{3}{*}{ Hardwall } & 56 & 2.9 & 4.3 & 4.0 \\
\hline & & & 62 & 2.9 & 4.3 & 4.6 \\
\hline & & & 68 & 2.9 & 4.3 & 4.5 \\
\hline \multirow{3}{*}{3} & \multirow{3}{*}{ Hardwall } & \multirow{3}{*}{ Treated } & 56 & 2.8 & 3.3 & 0.5 \\
\hline & & & 62 & 2.9 & 3.5 & 0.9 \\
\hline & & & 68 & 3.1 & 3.6 & 1.3 \\
\hline \multirow{3}{*}{4} & \multirow{3}{*}{ Treated } & \multirow{3}{*}{ Treated } & 56 & 6.4 & 7.6 & 6.4 \\
\hline & & & 62 & 6.6 & 7.8 & 6.5 \\
\hline & & & 68 & 6.9 & 7.9 & 6.9 \\
\hline
\end{tabular}

Table 5: CDUCT-LaRC predicted and measured sound power attenuations. Predictions with and without Wide Angle Approximation (WAA).

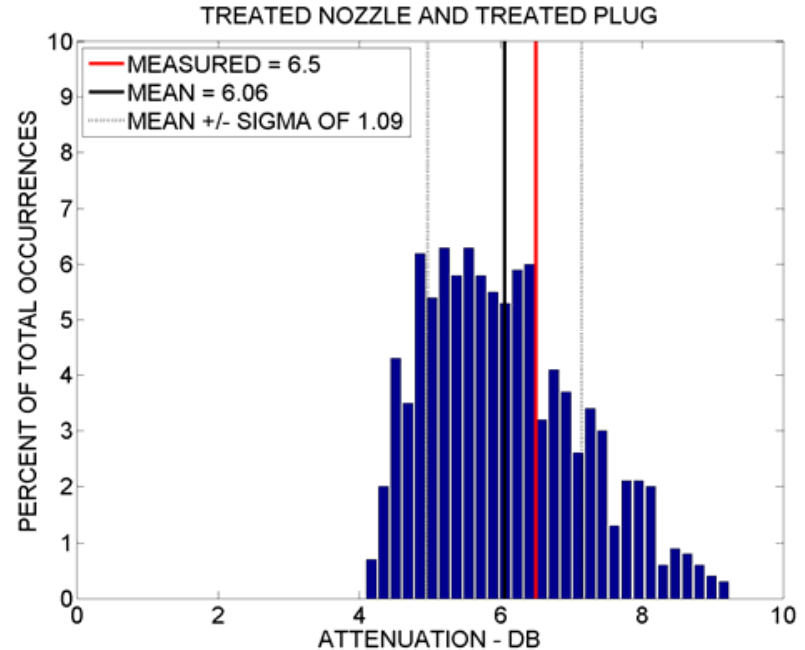

Figure 13: CDUCT-LaRC predicted attenuation for treated plug and nozzle, random phase, $62 \%$ design speed, $\mathrm{EO}=128$

\section{Summary}

NASA, Pratt \& Whitney and Goodrich have validated an approach for predicting turbine noise attenuation on a full-scale engine. The approach consists of three steps: (1) estimating the turbine-noise mode content, (2) computing the liner impedance based on the computed flow-field, and (3) computing in-duct propagation using high-fidelity codes such as the Eversman FEM code and CDUCT-LaRC. The predicted noise attenuation agreed to within $1 \mathrm{~dB}$ of the measured attenuation, except for one case. In that case, the 
discrepancy between the predicted and measured attenuation could be the result of uncertainty in the plug impedance. Further studies are needed to confirm this hypothesis.

In the noise propagation analysis, the modal phase assumption significantly impacts the predicted attenuation values. However, when averaged over a large number of randomphase assumptions, the predicted attenuations are in good agreement with the data. Therefore, the recommended approach is to randomly assign phase to each mode, run a multitude of random-phase assumptions, and use the mean value to represent the predicted attenuation.

With the wide-angle approximation, the CDUCT-LaRC results were within $0.5 \mathrm{~dB}$ of the Eversman FEM results. This result supports the use of CDUCT-LaRC for the predicting the noise attenuation of more complex 3D geometries (e.g. fan ducts with pylon and bifurcations) that cannot be handled with the 2D Eversman FEM code. Further studies are needed to validate the approach for more complex geometries on a full-scale engine.

\section{Acknowledgements}

The authors wish to acknowledge Amr Ali (P\&W) for performing the analysis to estimate the turbine noise modal content.

\section{References}

[1] G. Zlavog and W. Eversman. Source Effects on Realized Attenuation in Lined Ducts, AIAA Paper 2003-3247.

[2] Nark, D. M., Farassat, F., Pope, D. S., and Vatsa, V. .The Development of the Ducted Fan Noise Propagation and Radiation Code CDUCT-LaRC, AIAA Paper 2003-1652.

[3] E. W. Chien. A Theoretical Study on Aircraft Engine Acoustic Liner Optimization and Correlation with NASA Advanced Ducted Propulsor (ADP) Test, AIAA 20043032.

[4] Bass, H. E., Sutherland, L. C., Zuckerwar, A. J., Blackstock, D. T. and Hester, D. M., "Atmospheric Absorption of Sound: Further Developments", JASA, Vol. 97, pp. 680683, Jan 1995.

[5] Bass, H. E., Sutherland, L. C., Zuckerwar, A. J., Blackstock, D. T. and Hester, D. M., "Erratum: Atmospheric Absorption of Sound: Further Developments," JASA, Vol. 99, p. 1259, Feb 1996.

[6] Schlinker, R. H. and Amiet, R. K., "Refraction and Scattering of Sound by a Shear Layer,” NASA CR-3371, Dec. 1980.

[7] Venditti, D., Mehdizadeh, O., Joshi, N., and Ali, A. "Turbofan Duct-Mode Identification Using Farfield Noise Measurements and Numerical Predictions," AIAA2006-2641, 12th AIAA/CEAS Aeroacoustics Conference, Cambridge, Massachusetts, May 8-10, 2006

[8] H. W. Kwan, J. Yu, A. Abeysinghe, E.Chien, "A Review of Acoustic Treatment Design for Aircraft Engine Noise Reduction”, Inter Noise 2006, in06-284, Dec. 3-6 Honolulu, Hawaii, USA 